\title{
The dynamics and relationships of precipitation, temperature and convection boundaries in the dayside auroral ionosphere
}

\author{
J. Moen ${ }^{1,2}$, M. Lockwood ${ }^{3}$, K. Oksavik ${ }^{1}$, H. C. Carlson ${ }^{4}$, W. F. Denig ${ }^{5}$, A. P. van Eyken ${ }^{6}$, and I. W. McCrea ${ }^{3}$ \\ ${ }^{1}$ Department of Physics, University of Oslo, P.O. Box 1048, Blindern, N-0316 Oslo, Norway \\ ${ }^{2}$ Arctic Geophysics, University Centre in Svalbard, N-9170 Longyearbyen, Norway \\ ${ }^{3}$ Rutherford Appleton Laboratory, Chilton, Didcot, Oxon OX11 0QX, UK \\ ${ }^{4}$ Air Force Research Laboratory, AFOSR, 801 Stafford St., Arlington, VA 22203, USA \\ ${ }^{5}$ Air Force Research Laboratory, VSBXP, 29 Randolph Rd, Hanscom AFB, MA 01731-3010, USA \\ ${ }^{6}$ EISCAT Scientific Association, P.O. Box 164, Kiruna, Sweden
}

Received: 3 June 2003 - Revised: 5 January 2004 - Accepted: 9 February 2004 - Published: 14 June 2004

\begin{abstract}
A continuous band of high ion temperature, which persisted for about $8 \mathrm{~h}$ and zigzagged north-south across more than five degrees in latitude in the dayside (07:00 15:00 MLT) auroral ionosphere, was observed by the EISCAT VHF radar on 23 November 1999. Latitudinal gradients in the temperature of the F-region electron and ion gases $\left(\mathrm{T}_{e}\right.$ and $\mathrm{T}_{i}$, respectively) have been compared with concurrent observations of particle precipitation and field-perpendicular convection by DMSP satellites, in order to reveal a physical explanation for the persistent band of high $\mathrm{T}_{i}$, and to test the potential role of $\mathrm{T}_{i}$ and $\mathrm{T}_{e}$ gradients as possible markers for the open-closed field line boundary. The north/south movement of the equatorward $\mathrm{T}_{i}$ boundary was found to be consistent with the contraction/expansion of the polar cap due to an unbalanced dayside and nightside reconnection. Sporadic intensifications in $\mathrm{T}_{i}$, recurring on $\sim 10$-min time scales, indicate that frictional heating was modulated by time-varying reconnection, and the band of high $\mathrm{T}_{i}$ was located on open flux. However, the equatorward $\mathrm{T}_{i}$ boundary was not found to be a close proxy of the open-closed boundary. The closest definable proxy of the open-closed boundary is the magnetosheath electron edge observed by DMSP. Although $\mathrm{T}_{e}$ appears to be sensitive to magnetosheath electron fluxes, it is not found to be a suitable parameter for routine tracking of the open-closed boundary, as it involves case dependent analysis of the thermal balance. Finally, we have documented a region of newly-opened sunward convecting flux. This region is situated between the convection reversal boundary and the magnetosheath electron edge defining the openclosed boundary. This is consistent with a delay of several minutes between the arrival of the first (super-Alfvénic) magnetosheath electrons and the response in the ionospheric convection, conveyed to the ionosphere by the interior Alfvén wave. It represents a candidate footprint of the low-latitude boundary mixing layer on sunward convecting open flux.
\end{abstract}

Correspondence to: J. Moen

(jmoen@fys.uio.no)
Key words. Ionosphere (auroral ionosphere; particle precipitation; plasma convection; plasma temperature and density)

\section{Introduction}

Precise determination of the ionospheric footprint of the open-closed field-line boundary (OCB) is of critical importance in the continuous monitoring of solar-terrestrial interactions using ground-based remote sensing techniques. The F2-region electron temperature has been identified as the key parameter that can be measured by the incoherent scatter radar technique and which can give information about magnetosheath-like precipitation in the magnetospheric boundary layers, the cusp and the low-latitude boundary layer (LLBL). This is because the electron gas is effectively heated by low-energy magnetosheath precipitation. From the early operations of the Søndre Strømfjord radar, Wickwar and Kofman (1984) reported increased electron density and elevated electron temperature in the dayside F-region ionosphere. The electron heating in the cusp/LLBL region was inferred to be a persistent feature in a statistical survey of the topside ionosphere by Titheridge (1976) and has been directly observed by low-altitude satellite (Brace et al., 1982; Curtis et al., 1982). Incoherent scatter data confirm that it is frequently present (e.g. Watermann et al., 1994; Nilsson et al., 1996; McCrea et al., 2000; Pryse et al., 2000) and with high-time resolution (10 s) measurements, Lockwood et al. (1993) have shown that the cusp electron temperature enhancements can, at least sometimes, consist of a series of poleward-moving events, very similar to the behaviour of the red-line dayside auroral transients, another persistent feature of the dayside auroral ionosphere. Watermann et al. (1994) examined the ionospheric response to magnetosheath particle fluxes observed by DMSP, and compared their observations with model results (see also Davis and Lockwood, 1996). The observed enhancements in the 


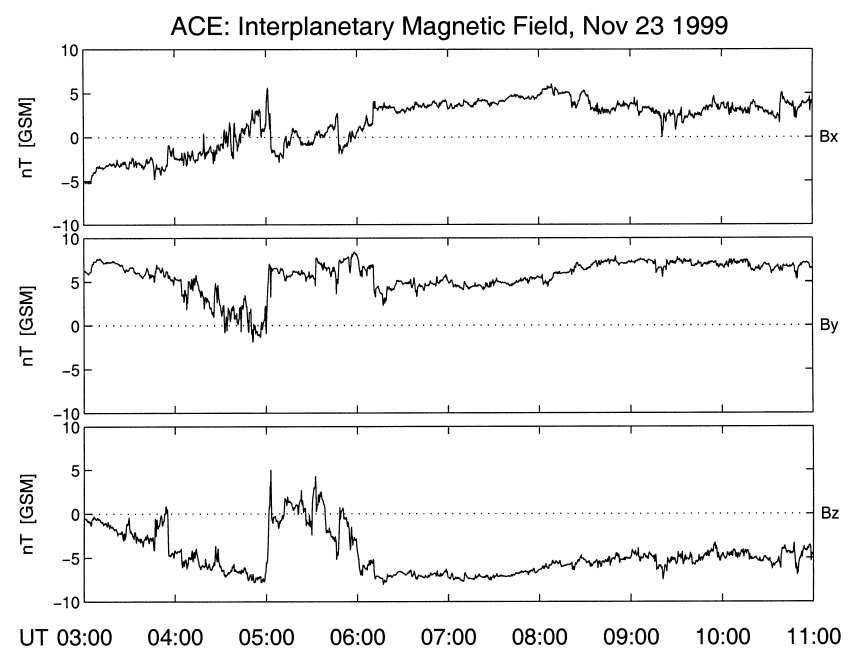

Fig. 1. The GSM components of the interplanetary magnetic field (IMF) measured by the ACE spacecraft near the first Lagrange point from 03:00-11:00 UT on 23 November 1999.

electron density (locally produced) and elevated electron temperatures were found to be in accordance with model predictions. Nilsson et al. (1996) carried out a multi-case study and subdivided the cusp/LLBL region into various "types" of magnetosheath particle injections. They found the sharp equatorward $\mathrm{T}_{e}$ boundary to be a unique cusp signature independent of the actual "type" of cusp activity. Sporadic enhancements in the ion temperature were sometimes observed in the vicinity, but not exactly coincident with the high $\mathrm{T}_{e}$. Doe et al. (2001) reported a seven-hour persistent high $\mathrm{T}_{e}$ observed between $300-500 \mathrm{~km}$ altitudes, with a sharp fieldaligned equatorward boundary near the equatorward edge of DMSP cusp detections. They pointed out, however, that the $\mathrm{T}_{e}$ cusp signature may be suppressed due to electron cooling below $400 \mathrm{~km}$. A recent model study by VontratReberac (2001) demonstrated that cusp electrons may heat the ambient electron gas by typically $750-1000 \mathrm{~K}$, and give rise to much larger temperature enhancement than precipitations from any other source regions. Pryse et al. (2000) conducted a multi-instrument study of ionospheric footprints of dayside reconnection, and found that a boundary of high $\mathrm{T}_{e}$ observed by EISCAT was nearly collocated with the highenergy edge of a cusp ion dispersion signature observed by DMSP, giving further support to the prediction that a sharp $\mathrm{T}_{e}$ gradient is a potential marker of the open-closed field-line boundary.

Model work by Lockwood and Fuller-Rowell (1987a, b) predicted that a band of strong Joule heating and high $\mathrm{T}_{i}$ will form on the poleward side of an expanding flow-reversal boundary, where newly-opened flux moving anti-sunward would initially meet sunward neutral winds. Similarly, for a contracting polar cap, a high $\mathrm{T}_{i}$ band is expected to form at the equatorward side of a contracting flow-reversal boundary. Lockwood et al. (1988) and Fox et al. (1994) found experimental evidence for this effect in contracting polar cap boundaries near dawn and dusk, and the idea has since been used as a rationale for identifying the open-closed field-line boundary (Davies et al., 2002), or used as an indicator of the flow-reversal boundary itself (Woodfield et al., 2002).

On 23 November 1999, EISCAT VHF observed a more-orless continuous band of high $\mathrm{T}_{i}$, which moved back and forth across the radar field-of-view (f-o-v) in the north-south direction several times between about 04:20 to 12:00 UT, forming a zigzag pattern on latitude-time displays. A corresponding well-defined $\mathrm{T}_{e}$ gradient was not observed, although the two DMSP snapshots revealed that $\mathrm{T}_{e}$ was elevated near the equatorward edge of magnetosheath electron precipitation, which is a key signature of the open-closed field line boundary (hereafter termed OCB). The data set provides compelling evidence that for southward IMF $\left(\mathrm{B}_{Z}<0\right)$, the convection reversal boundary (hereafter termed the $C R B$ ) can be poleward of the OCB, giving sunward-convecting open LLBL flux between the OCB and the CRB. Such an effect was predicted by Lockwood (1998), who suggested that the ionospheric end of a newly-opened field line will continue to flow sunward until the arrival of the interior Alfvén wave, the arrival of which would mark the equatorward edge of the CRB.

\section{Observations}

Figure 1 shows the $\mathrm{X}, \mathrm{Y}$ and $\mathrm{Z}$ components of the interplanetary magnetic field (IMF) in the Geocentric Solar Magnetospheric (GSM) frame recorded by ACE during the interval 03:00-11:00 UT, on 23 November 1999. From 03:00 UT to about 04:30 UT, $\mathrm{B}_{X}$ increased from $-5 \mathrm{nT}$ to zero. It then fluctuated between $-3 \mathrm{nT}$ and $+3 \mathrm{nT}$ until about 06:10 UT, after which it remained positive until the end of the interval. The IMF $\mathrm{B}_{Y}$ component was positive and larger than $5 \mathrm{nT}$ most of the time, except after 04:00 UT, when it decreased from near $5 \mathrm{nT}$ to near zero, about which it fluctuated until it abruptly increased to $7 \mathrm{nT}$ at 05:00 UT. The IMF $\mathrm{B}_{Z}$ component was predominantly negative. Between 03:00 and 05:00 UT it gradually decreased from zero to $-7.5 \mathrm{nT}$. A sharp northward transition occurred at 05:00 UT, from $-7.5 \mathrm{nT}$ to $5 \mathrm{nT}$. Then it changed polarity several times with increasing amplitude, ending with a prominent +5 to $-5 \mathrm{nT}$ bipolar transition between 05:30 and 05:50 UT. From 05:50 to about 06:00 UT it decreased from zero to $-7 \mathrm{nT}$, and thereafter remained strongly negative. The time lag between the $\mathrm{ACE}$ and the EISCAT observations is computed from the observed solar wind speed to be about $1 \mathrm{~h}$, and in Sect. 3.1 we show that this is consistent with observed signatures of IMF changes in the EISCAT data. In particular, the abrupt change in $\mathrm{B}_{Y}$ and $\mathrm{B}_{Z}$ can be identified in the radar data with this lag.

The EISCAT VHF radar is situated in Tromsø in northern mainland Norway and on 23 November 1999 was operated in a split-beam configuration with two northward pointing beams at $30^{\circ}$ elevation making observations above Svalbard archipelago. Figures $2 \mathrm{a}-2 \mathrm{~d}$ show the plasma parameters observed along Beam 1 from 04:00-12:00 UT. The data are colour-coded according to the scales given in magnetic 
a)
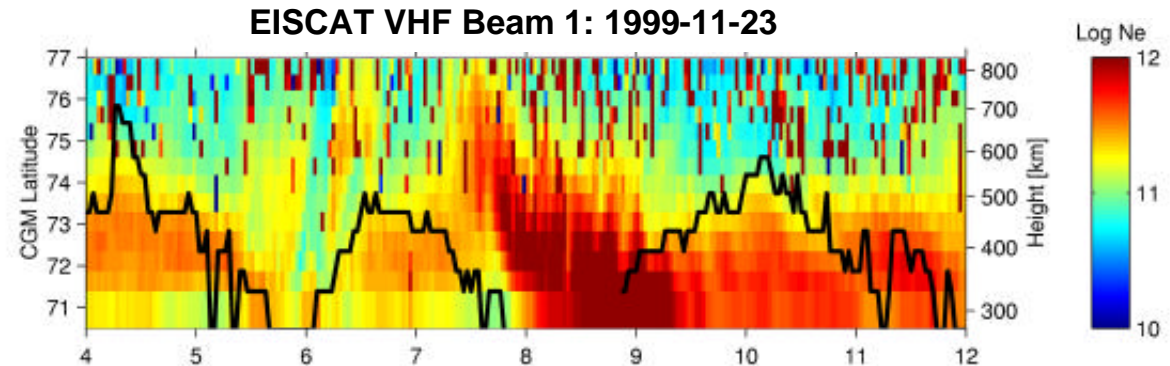

b)
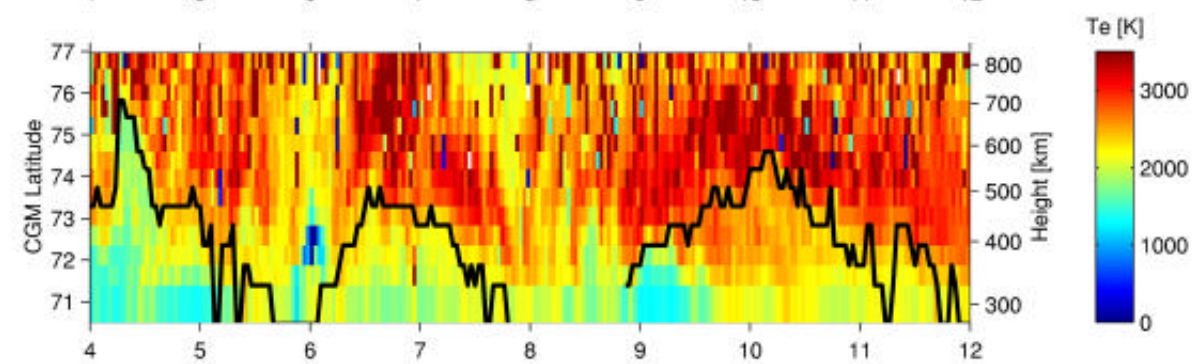

c)
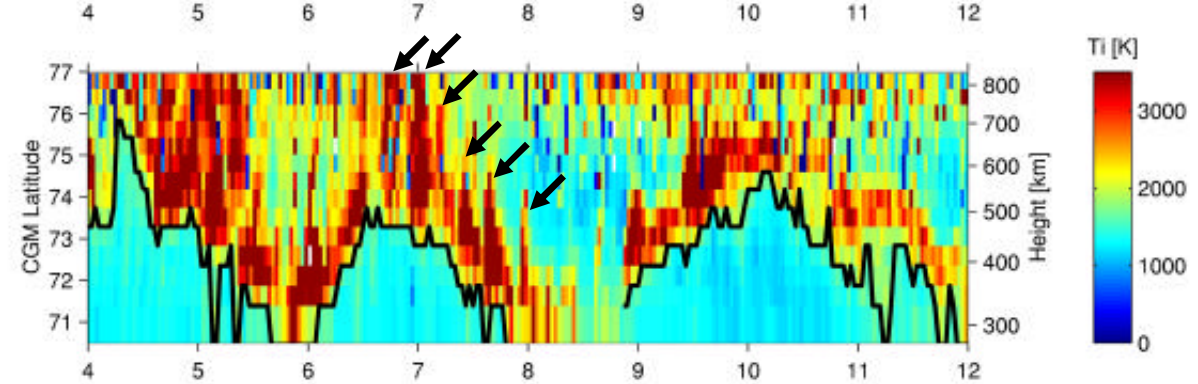

d)

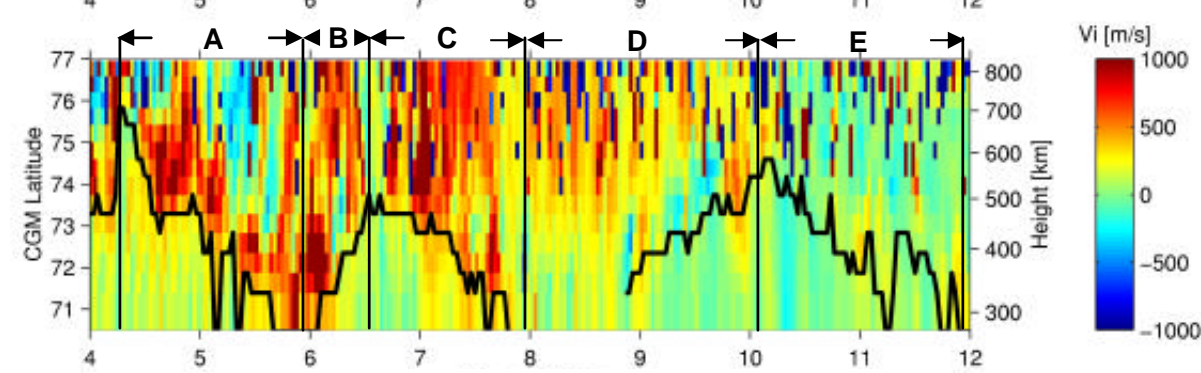

e)

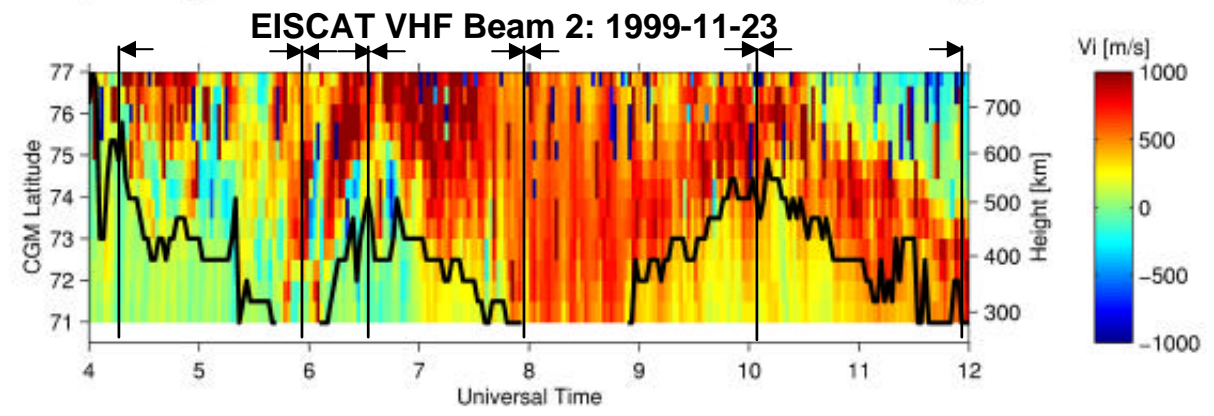

Fig. 2. Plasma parameter plots obtained by EISCAT VHF in a V-shape configuration above Svalbard at $30^{\circ}$ elevation. Panels (a)-(d) show the electron density, electron temperature, ion temperature and line-of-sight ion velocity for the boresite Beam 1 pointing $15^{\circ}$ east of geographic north. The bottom panel (e) shows the line-of-sight ion velocity for the phase-shifted beam pointing towards geographic north. Positive velocity means away from the radar (poleward).

(CGM) latitude - observation time format. Note that, because the beams are at $30^{\circ}$ elevation, the height of the observations varies from near $250 \mathrm{~km}$ at $70^{\circ}$ latitude to near $800 \mathrm{~km}$ at $77^{\circ}$ latitude. The data shown are: the electron concentration, $\mathrm{N}_{e}$, in Fig. $2 \mathrm{a}$; the electron temperature, $\mathrm{T}_{e}$, in Fig. 2b; the ion temperature, $\mathrm{T}_{i}$, in Fig. $2 \mathrm{c}$; and the line- of-sight (l-o-s) ion velocity, $\mathrm{V}_{i}$, in Fig. $2 \mathrm{~d}\left(\mathrm{~V}_{i}>0\right.$ is defined as away from the radar). In order to ease the comparison between Beam 1 and Beam 2, the 1-o-s velocity from Beam 2 is presented in Fig. 2e. The other plasma parameters are almost identical to Beam 1 and are therefore not presented. 
The azimuth angles for Beam 1 and Beam 2 were, respectively, $359.8^{\circ}$ and $344.8^{\circ}$ east-of-north. The geometry is displayed in Fig. 3a, where the dotted curves represent constant CGM latitude (L-shells) from 66-86 in 4-degree intervals. Beam 2 is directed towards the magnetic pole, while Beam 1 is pointing towards geographic north and makes an angle $15^{\circ}$ toward magnetic east with respect to Beam 2 . The outstanding feature that drew our attention to the data presented in Fig. 2 is the narrow channel of enhanced $T_{i}$ zigzagging north-south over more than five degrees in magnetic latitude, several times in the interval shown. The black curve superimposed on the upper four panels represents the $\mathrm{T}_{i}=1700 \mathrm{~K}$ iso-contour line extracted from the equatorward edge of the high $\mathrm{T}_{i}$ band in Fig. 2c. The black contour superimposed on the Beam 21 -o-s velocities in Fig. 2e is the corresponding $\mathrm{T}_{i}=1700 \mathrm{~K}$ boundary derived for Beam 2 . Before looking into more detailed plasma characteristics with emphasis on two DMSP satellite passes, we would like to describe the general flow picture observed as the radar progressed in magnetic local time from near 07:00 to 15:00 MLT (MLT=UT+3 h) under a two-cell flow pattern. As the governing IMF condition was $\mathrm{B}_{Y}$ positive and $\mathrm{B}_{Z}$ negative, we expect a two-cell flow pattern with a large afternoon cell and a crescent-shaped morning cell (Heppner and Maynard, 1987). A subdivision of the full period into five time intervals, A-E, are marked by vertical lines on Figs. $2 \mathrm{~d}$ and $2 \mathrm{e}$.

During interval A, from 04:20 to 06:00 UT, the $\mathrm{T}_{i}$ channel migrated equatorward. Beam 1 , directed $15^{\circ}$ east of the magnetic meridian, experienced a strongly enhanced flow away from the radar $\left(\mathrm{V}_{i}>0\right)$ immediately poleward of the $\mathrm{T}_{i}=1700 \mathrm{~K}$ boundary. When not interrupted by strong poleward flows a prominent flow shear is situated within or near the poleward boundary of the high $\mathrm{T}_{i}$ band: poleward of this shear $\mathrm{V}_{i}<0$ (compare Figs. 2c and 2d). Beam 2 saw the same flow shear, but with the polarities of $\mathrm{V}_{i}$ reversed in that weak toward flow was seen within the $\mathrm{T}_{i}$ channel and a large away flow poleward of it. This is consistent with both beams looking eastward across a crescent-shaped convection dawn cell, as expected for the observed positive IMF $\mathrm{B}_{Y}$. Beam 2, oriented more closely to the magnetic meridian, picked up a relatively strong northward component of the anti-sunward flow, poleward of the CRB. The weak toward flow equatorward of the CRB indicates that Beam 2 had a small westward tilt relative to the convection-reversal boundary. At the end of interval A, at around 05:40 UT, the convection reversal disappeared. Instead we see two prominent events of enhanced poleward flow. In Beam 1, the two events first appeared near the $\mathrm{T}_{i}$ boundary at 05:42 UT and 05:55 UT (Fig. 2d) and progressed poleward over the entire latitude range. In Beam 2, these onsets occurred a few minutes later, but are outstandingly clear at 05:46 UT and 06:00 UT. Both events appear associated with plasma density patches observed in Fig. 2a. These are signatures expected of reconnection pulses or "flux transfer events" (FTEs; Moen et al., 2001; Lockwood et al., 2001), indicating that the radar experienced plasma convecting away from the cusp region.
The $\mathrm{T}_{i}$ boundary retreated poleward immediately after the onset of the second transient event and moved poleward until 06:35 UT (interval B). During interval C (06:35-08:00 UT), the $\mathrm{T}_{i}$ boundary migrated equatorward again to a location to the south of the radar f-o-v. After 07:00 UT strong away flow is seen in both radar beams poleward of the $\mathrm{T}_{i}$ boundary (black line) with weaker away flow equatorward of it. The away flow becomes gradually weaker in Beam 1 but is only slightly reduced in Beam 2, indicating that Beam 1 started to experience less longitudinal flow but the poleward flow is maintained as the radar $\mathrm{f}-\mathrm{o}-\mathrm{v}$ moves into the afternoon convection cell. In Fig. $2 \mathrm{a}$ we see that a "tongue" of enhanced ionization is being fed into the polar cap between 07:30 and 09:00 UT. This tongue exhibits poleward-moving fine structure which has been studied in greater detail by Davies et al. (2002), who show that it matches up closely with poleward-moving events seen simultaneously and in the same region in HF backscatter echoes observed by the CUTLASS radar. The tongue of ionization seen in the electron density is another indicator that solar EUV ionized plasma drifted into the polar cap from the dusk sector. Some time after 08:00 UT (interval D) the polar-cap boundary retreated poleward once more, but the movement is not apparent in the ion temperature until $\mathrm{T}_{i}$ increased above the $1700 \mathrm{~K}$ threshold set for boundary tracing at 08:55 UT. Notably, the ion temperature is low near the local noon at 08:50 UT. Strong away flows $\left(0.5-1 \mathrm{~km} \mathrm{~s}^{-1}\right)$ were maintained along the entire range of Beam 2. Around 09:00 UT Beam 1 started to see significant toward flow within the $\mathrm{T}_{i}$ channel, and a flow reversal near the poleward boundary of the $\mathrm{T}_{i}$ channel is relatively well-defined between 09:10-09:45 UT, while Beam 2 is seeing strong away flow at all latitudes above the lowlatitude edge of the $T_{i}$ enhancement. This is consistent with Beam 2 looking along convection streamlines flowing into the polar cap, while Beam 1 observes the CRB of the more circular dusk cell for IMF $\mathrm{B}_{Y}>0$. Beam 2 also saw the afternoon cell CRB from 10:30 UT onwards when it was absent in Beam 1 (period $\mathrm{E}$, in which the boundary is expanding equatorward again).

In summary, the radar data are broadly consistent with the radar rotating, with the Earth under the form of the convection pattern expected for the IMF orientation that was observed to prevail throughout most of the interval studied $\left(\mathrm{B}_{Y}>0\right.$ and $\left.\mathrm{B}_{Z}<0\right)$. However, the pattern is far from steady in form and the channel of enhanced $\mathrm{T}_{i}$, in which the CRB is embedded, is seen to migrate polewards and equatorwards over the radar field-of-view.

Against this background of the convection pattern and its variations, let us now have a detailed look at EISCAT boundary observations associated with two DMSP satellite passes close to the radar f-o-v. Figure $3 \mathrm{a}$ demonstrates the path of DMSP F13 as it passed to the east of the EISCAT VHF beams around 06:29 UT. The precipitating electron and ion fluxes measured along this path are presented in the upper two panels of Fig. 3b. DMSP F13 had two encounters of cusp-like precipitation, one centred on 06:24 UT (14:36 MLT), and the other one at 06:28 UT (11:06 MLT). It is the latter encounter 
a)

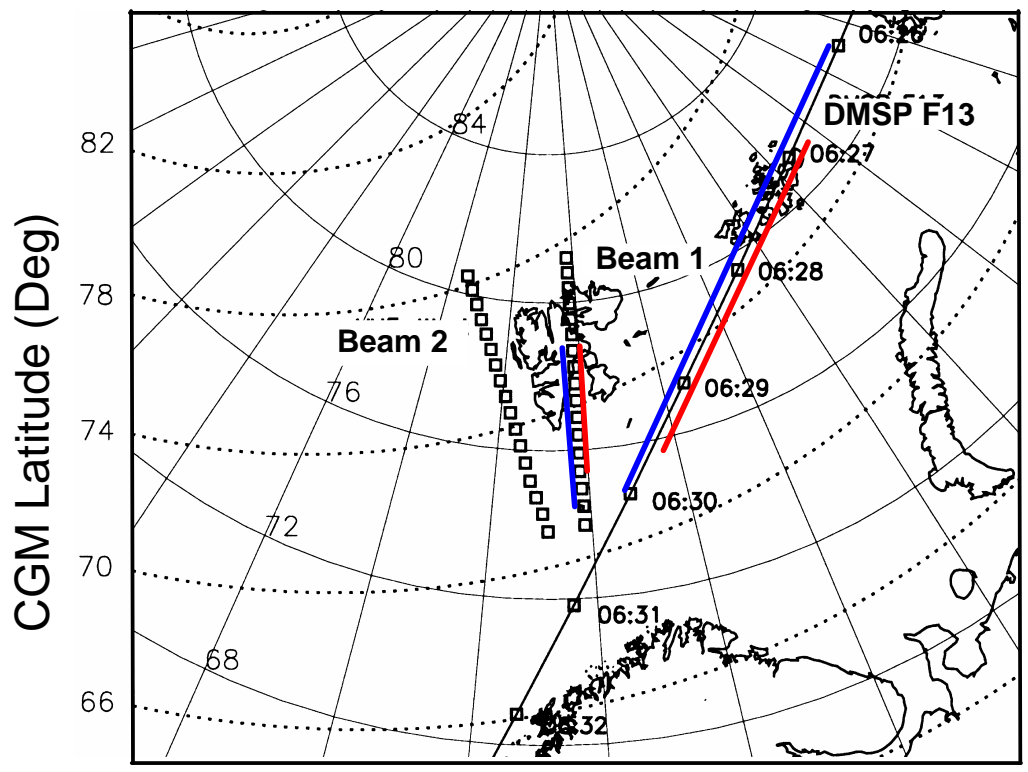

b)
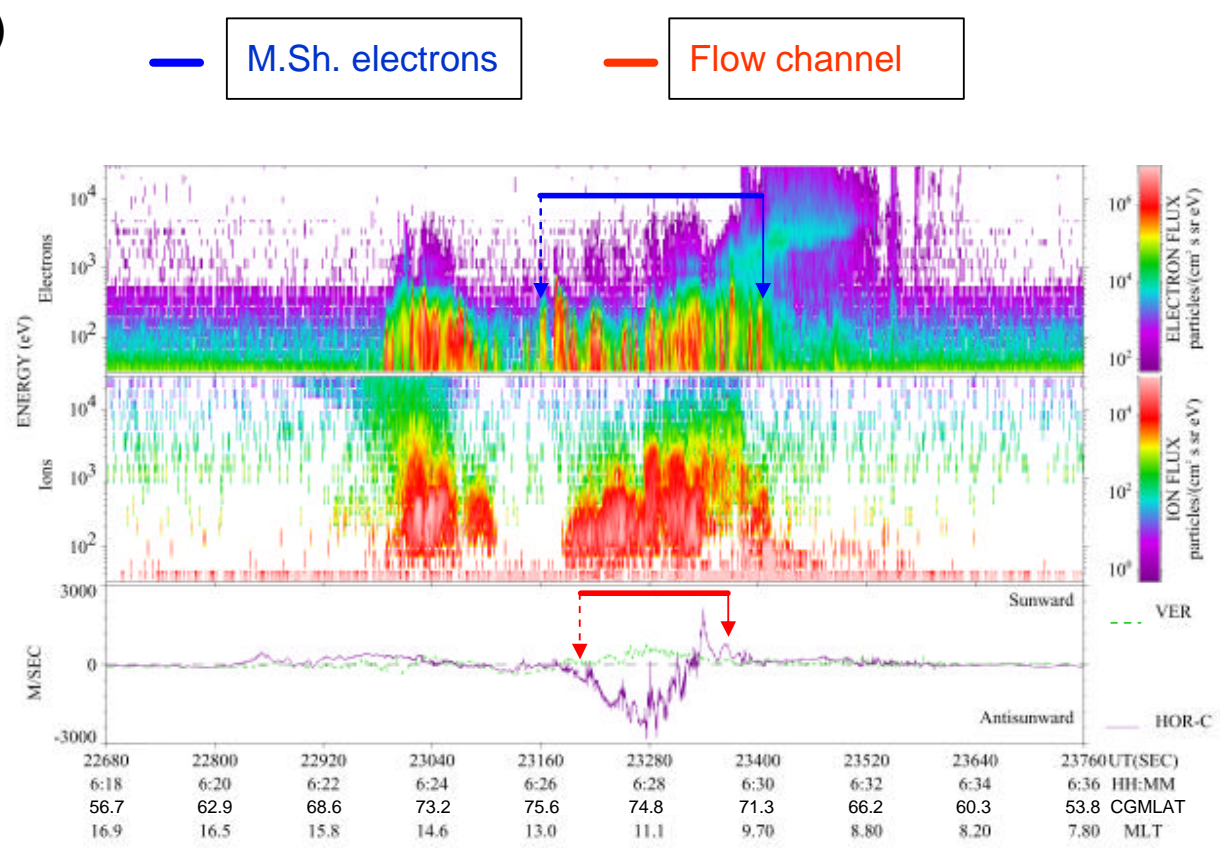

Fig. 3. (a) The geometry of the DMSP F13 pass east of EISCAT's Beam 1 and Beam 2 around 06:30 UT. The blue bar along the satellite trajectory marks the spatial extent of magnetosheath electron precipitation, and the red bar marks the extent of a convection flow channel observed by the satellite. These bars have been mapped along the L-shells onto Beam 1 and will be compared with electron and ion gas temperatures measured by EISCAT. (b) Electron and ion precipitation fluxes and cross-track (magenta) and vertical (green) flows measured by the drift meter on board DMSP. The blue bar corresponds to the blue bars in (a), and the solid arrow (dashed arrow) marks the equatorward (poleward) edge of intense magnetsheath-like electron precipitation. The red bar and arrows mark out the convection channel to be compared with enhanced EISCAT $\mathrm{T}_{i}$ measurements.

of cusp precipitation that is of particular interest for comparison with EISCAT because it is close to the radar f-o-v. We would like to check whether the high $\mathrm{T}_{i}$ band is related to a flow channel, and we would also like to see if the edge of magnetosheath electron precipitation is associated with a well-defined boundary of enhanced $\mathrm{T}_{e}$. Based on two satel- lite passes it is of course not possible to establish a quantitative approach for this comparison. However, the equatorward edge of magnetosheath electron precipitation is rather well defined. In Fig. $3 b$ the equatorward edge is marked by a blue arrow, and the poleward edge is indicated by a dashed blue arrow. These two arrows are connected with a blue bar which 

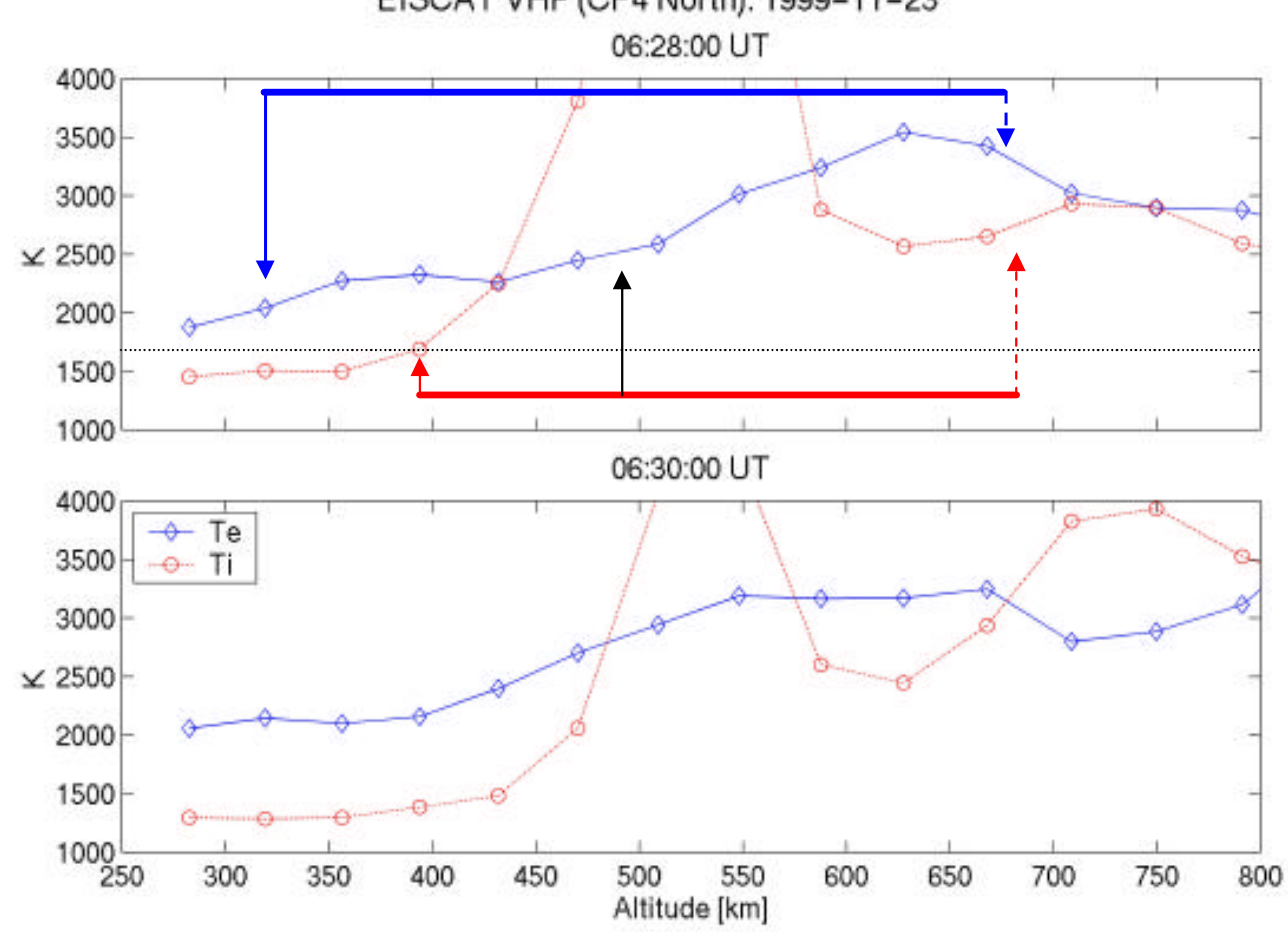

Fig. 4. The $\mathrm{T}_{e}$ (red curve) and $\mathrm{T}_{i}$ (blue curve) versus altitude along Beam 1 for data integration periods commencing at 06:28 and 06:30 UT. The blue and the red bars are corresponding to Fig. 3 and mark out the regions of magnetosheath electron precipitation and the plasma flow channel measured by DMSP F13. The flow reversal boundary is indicated by the black arrow. The horizontal dashed line is a guideline for the $\mathrm{T}_{i}=1700 \mathrm{~K}$ boundary.

has been transferred to the satellite trajectory in Fig. 3a, and mapped along the magnetic L-shells onto VHF Beam 1. The satellite trajectory and the radar gate positions have been transformed to the Corrected GeoMagnetic (CGM) coordinates. Figure 4 presents ion temperature (red) and electron temperature (blue) observed along radar Beam 1 . The variation is a function of range, which mixes altitudinal and latitudinal variations. In the vertical axes of Fig. 4 we use height to remind us that this is also a relevant factor. Figure 4 shows data from two successive 2-min data integration periods commencing at 06:28 UT and 06:30 UT. The latitudinal variation in both temperatures is superposed as an upward trend that is caused by the increase in altitude of the beam. This altitude effect will be greater for the electron temperature. However, we can note that the equatorward boundary of the lowenergy electron precipitation is related to a significant gradient in the electron temperature on the 06:28 UT profile. In the 06:30 UT profile a significant $\mathrm{T}_{e}$-gradient was observed two range gates further north, i.e. at range gate 4 around $390 \mathrm{~km}$ altitude. In the bottom panel of Fig. $3 \mathrm{~b}$ we see that the cusp precipitation east of EISCAT Beam 1 was associated with strongly enhanced cross flow. The horizontal cross-track component is indicated in magenta (positive sunward), and the vertical drift is plotted in green (positive up). Horizontal flow speeds of up to $2 \mathrm{~km} \mathrm{~s}^{-1}$ are observed. Since we have chosen $1700 \mathrm{~K}$ to delineate the equatorward boundary of the Joule-heating channel, it would be interesting to see what it corresponds to in terms of DMSP flow data. From the $\mathrm{T}_{i}$ curve in Fig. 4 we see that the $1700 \mathrm{~K}$ boundary corresponds to the red arrow at $390 \mathrm{~km}$ altitude (gate 4). Mapped onto the satellite track this corresponds to the right-hand red arrow placed at 06:29:30 UT which points out a local maximum in the return flow of $0.9 \mathrm{~km} \mathrm{~s}^{-1}$. The left-hand red arrow represents the $0.9 \mathrm{~km} \mathrm{~s}^{-1}$ threshold at the poleward boundary near 06:26:15 UT. Mapped backwards onto the radar beam this correspond to $680 \mathrm{~km}$ just poleward of gate 11 . Between 06:26 and 06:27 the satellite nearly skimmed the L-shell and hence, the poleward boundary of the flow channel and the poleward boundary of the magnetosheath electron precipitation map to almost the same position along the radar beam. In the discussion we will focus on the equatorward boundaries only since the poleward boundaries (dashed arrows) are involved with large uncertainties. However, it is worthwhile to notice that the CRB is embedded in the flow channel/ high $\mathrm{T}_{i}$ and that the sense of flow geometry is consistent with what we postulated based on the EISCAT observations. In Fig. 4 the flow reversal is indicated by the black arrow.

DMSP F12 passed along a similar trajectory $2.5 \mathrm{~h}$ later, around 09:01 UT, as depicted in Fig. 5a. The observations made during this pass are presented in Fig. 5 b. The F12 satellite traversed a well-defined electron edge near 09:01:20 UT, although precipitating fluxes of magnetospheric electrons were weak immediately poleward of that edge. The ion data show a stepped ion dispersion signature with its high-energy 
a)

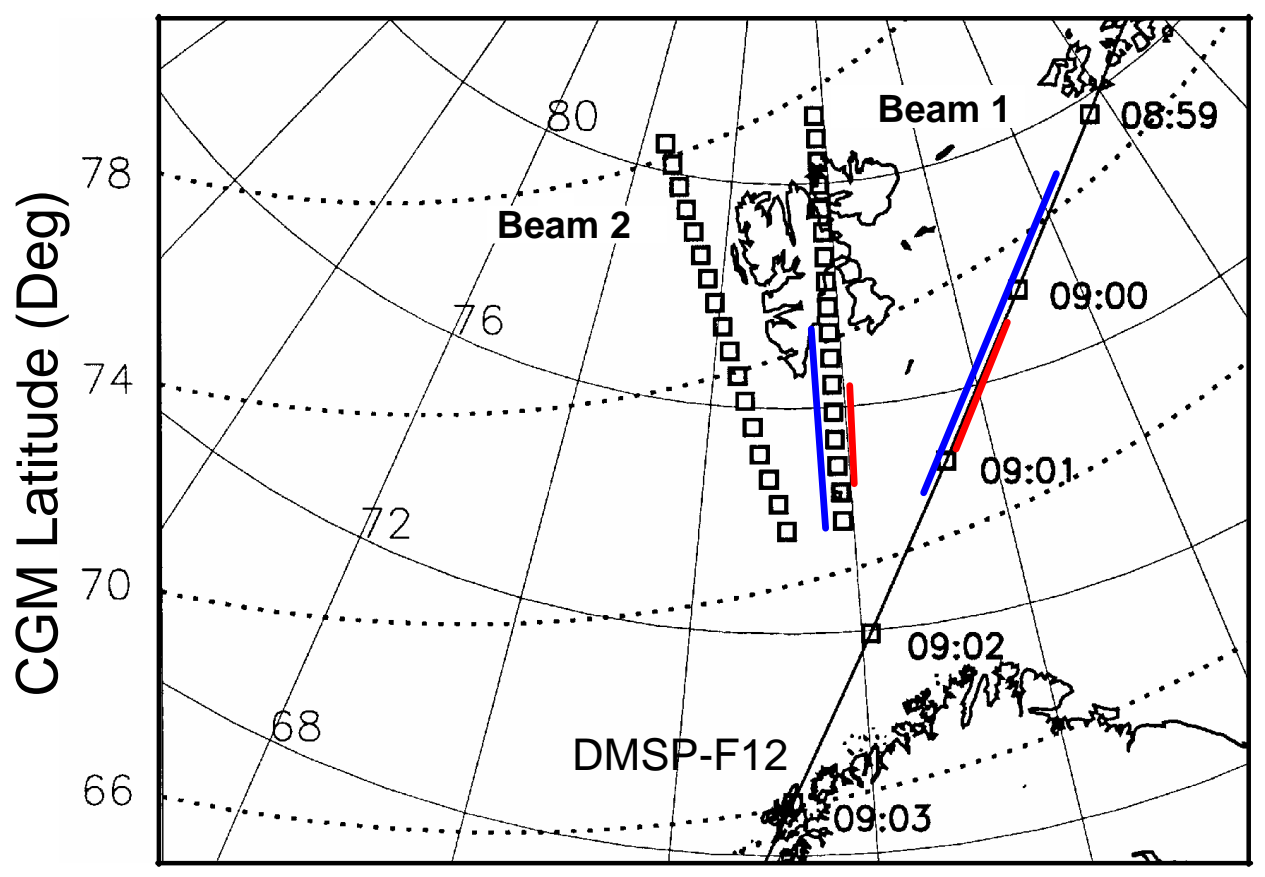

b) $\quad-$ M.Sh. electrons - Flow channel

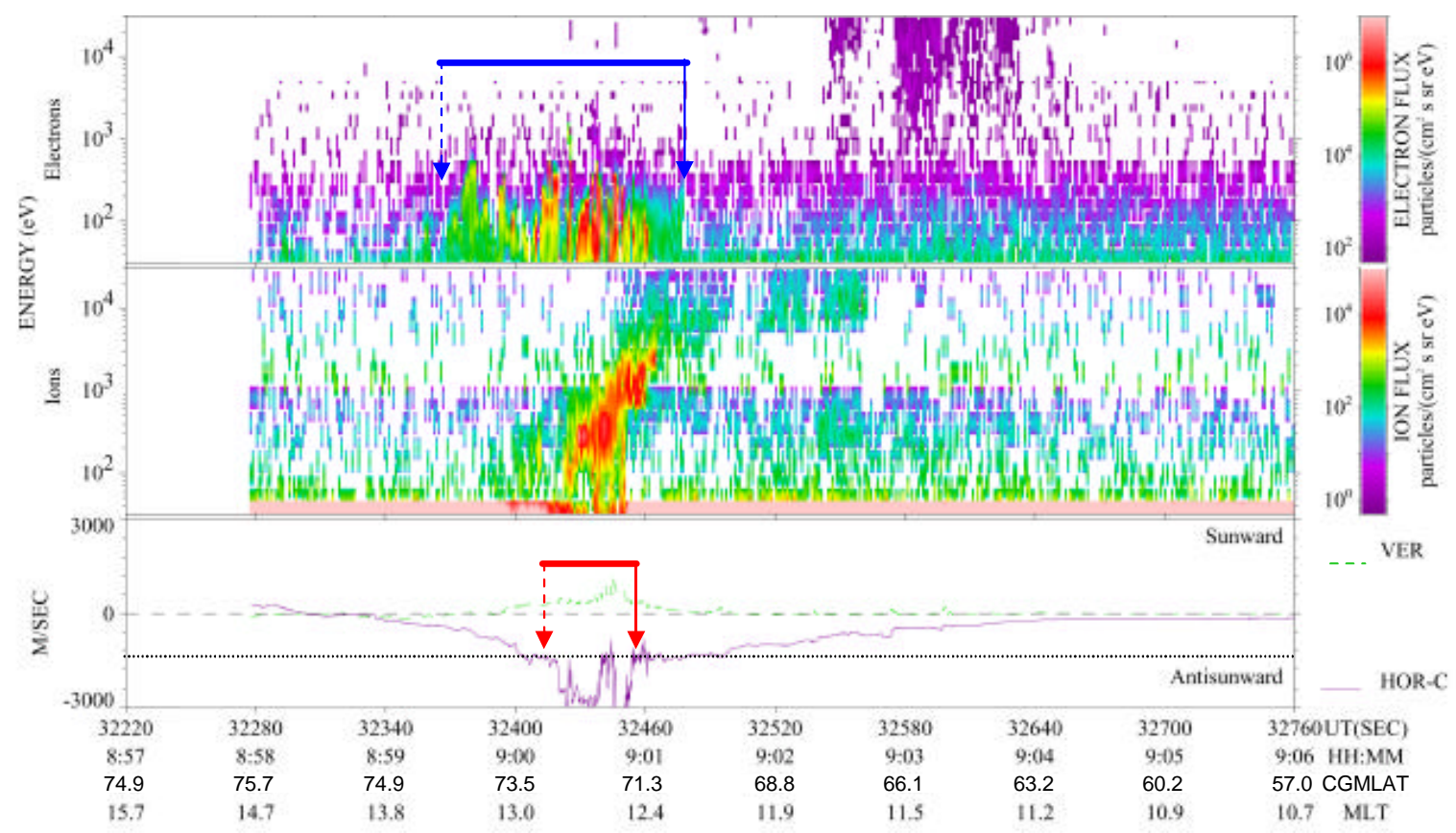

Fig. 5. Similar presentation as in Fig. 3 but for the DMSP F12 pass at around 09:00 UT.

edge located poleward of the magnetosheath electron edge. As in the previous example, the band of magnetosheath electron precipitation has been projected along L-shells onto the EISCAT VHF Beam 1 in Fig. 5a. Figure 6 presents $\mathrm{T}_{i}$ (red curve) and $\mathrm{T}_{e}$ (blue curve) along the beam (as for
Fig. 4, shown as a function of height) for the data integrations commencing at 09:00:00 UT and 09:01:59 UT. Temperatures above $4000 \mathrm{~K}$ are bad fits. Steep gradients are seen in both $\mathrm{T}_{e}$ and $\mathrm{T}_{i}$, and these are contracting poleward with time (see also Fig. 2). In this case the electron edge is right at 

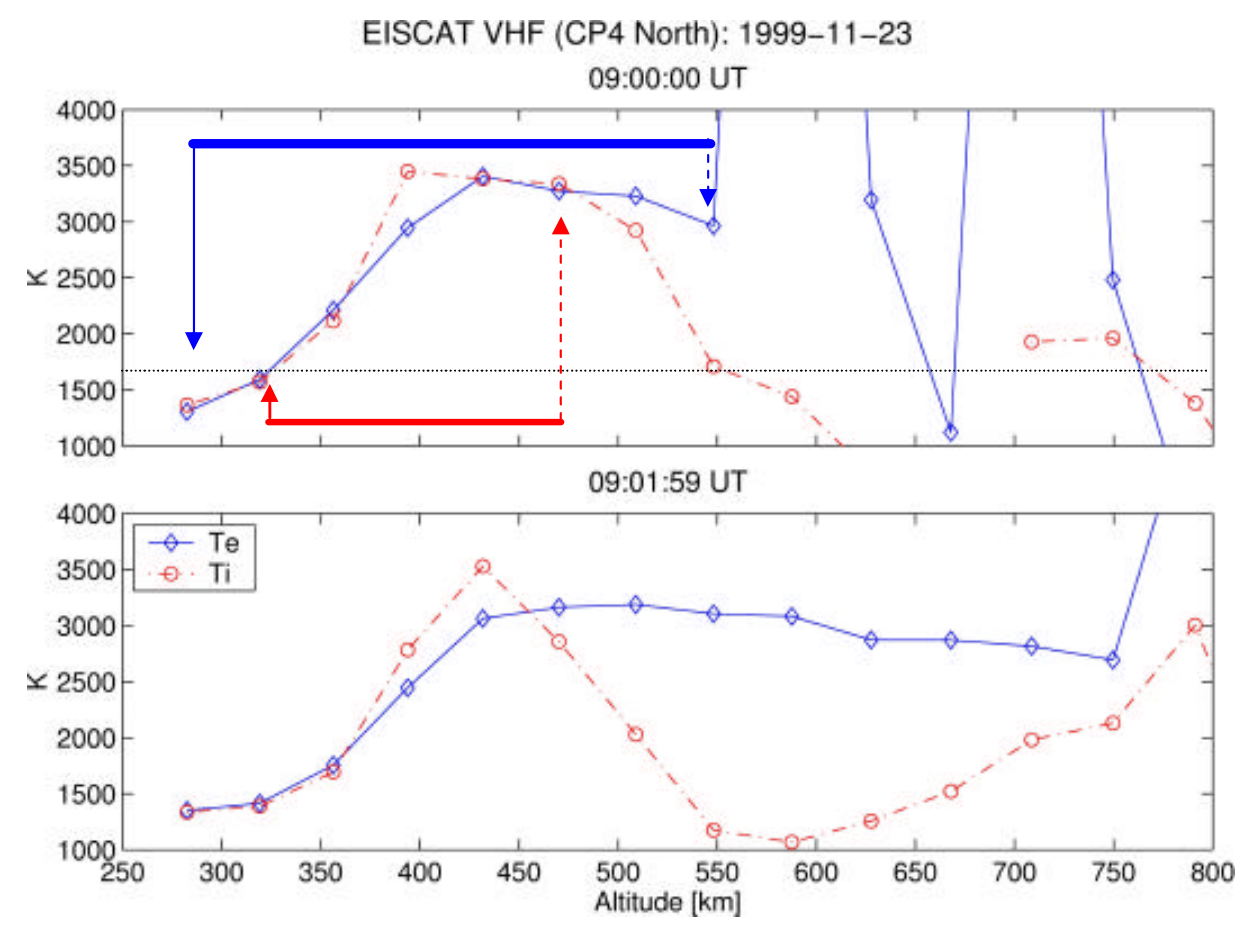

Fig. 6. The $\mathrm{T}_{e}$ and $\mathrm{T}_{i}$ versus height along EISCAT Beam 1 for 09:00 and 09:01:59 UT data records.

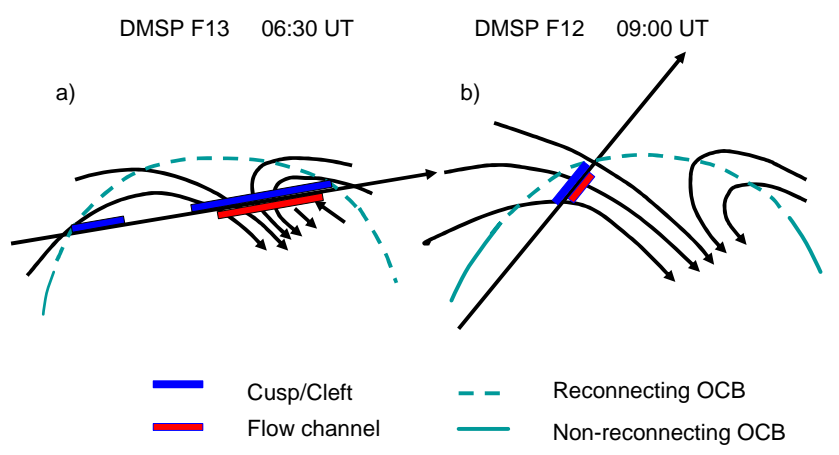

Fig. 7. Diagrams summarizing the information derived from the two satellite passes. Notably, the flow-reversal boundary observed on the prenoon sector of the F13 pass was located $\sim 300 \mathrm{~km}$ poleward of the open-closed field-line boundary, which is evidence of sunward return flow along open field lines.

the equatorward limit of the $\mathrm{f}-\mathrm{o}-\mathrm{v}$, but $\mathrm{T}_{e}$ seems to be sensitive to even modest fluxes of magnetosheath electrons. Associated with the cusp crossing, DMSP observed two bursts of strongly enhanced flows peaking above $3 \mathrm{~km} \mathrm{~s}^{-1}$. The $\mathrm{T}_{i}=1700 \mathrm{~K}$ boundary near gate 2 corresponds to the equatorward edge of the strong flow disturbance which appear superimposed onto a background flow of $\sim 1.4 \mathrm{~km} \mathrm{~s}^{-1}$ antisunward. We tentatively define the flow channel/Joule heating region to include both high speed streams. Mapping the poleward boundary (dashed arrow) back to EISCAT Beam 1 it corresponds to gate 6 , poleward of which there is a significant decrease in $\mathrm{T}_{i}$.

\section{Discussion}

The flow and precipitation patterns that are inferred from the snapshots provided by the two DMSP passes are schematically summarised in Fig. 7. The red bar is consistent with the band of high $\mathrm{T}_{i}$, as seen by EISCAT at these times, and the schematics are consistent with the inference from the EISCAT velocity data that the CRB is within the high- $\mathrm{T}_{i}$ band for both beams at 06:30 UT and for Beam 2 at 09:00 UT, but that the $\mathrm{CRB}$ is at the equatorward edge of the high- $\mathrm{T}_{i}$ band at 09:00 UT for Beam 1. For the IMF orientation (with $\mathrm{B}_{Y}>0$ and $\mathrm{B}_{Z}<0$ ) the $\mathrm{CRB}$ is most apparent in the dawn cell, and we conclude that both beams were observing the dawn cell at 06:30 UT, and around 09:00 UT Beam 2 was situated in the dawn cell, whereas Beam 1 was situated in the dusk cell.

As illustrated in Fig. 7a, DMSP F13 first encountered magnetosheath precipitation (blue bar) with weak cross-track drift in the 14:00-15:00 MLT sector. The DMSP satellites carry a Retarding Potential Analyser (RPA) to measure along-track plasma speed. In this case the data quality was poor, and the only information we have about convection is the lack of significant cross-track flow, indicating that the satellite path was close to being aligned with the convection streamlines. After a brief excursion poleward of the cusp, it traversed the cusp precipitation region for a second time, this time in the 10:00-12:00 MLT sector. This indicates that the width of the cusp was at least five hours in MLT at this time. The very strong anti-sunward flow observed during the prenoon cusp encounter $\left(2-3 \mathrm{~km} \mathrm{~s}^{-1}\right)$ and the lack of a clear ion dispersion signature (cf. Fig. 3b) is consistent 
with the satellite path in the second cusp intersection being almost perpendicular to the flow streamlines (so the alongtrack flow component must have been small here). The band of cusp precipitation extends on either side of the convection channel $\left(>1 \mathrm{~km} \mathrm{~s}^{-1}\right)$ marked in red. It is particularly interesting to see such clear evidence of sunward flow on field lines showing cusp particle precipitation, equatorward of CRB but poleward of the magnetosheath electron edge. The flow-reversal boundary is $2.7^{\circ}(300 \mathrm{~km})$ poleward of the electron edge, which is taken to be an indicator of the openclosed field-line boundary (Sandholt et al., 2002). The electron edge appears to coincide with elevated $\mathrm{T}_{e}$ in magnetic latitude, while the $T_{i}=1700 \mathrm{~K}$ boundary (equatorward edge of the flow channel) was located $1.2^{\circ}(130 \mathrm{~km})$ poleward of the electron edge.

The DMSP F12 pass illustrated in Fig. 7b made more like a meridional cut through cusp precipitation in the postnoon sector where it observed a strong cross-track flow. In this case we see prominent ion dispersion and steps in the ion energy cutoff. The $\mathrm{T}_{i}$ gradient observed by EISCAT coincided with the equatorward edge of strongly enhanced ion convection (Fig. 6). In this case the electron edge was corresponding to the southernmost radar gate, which makes it impossible to define a temperature boundary. However, the sharp gradient in $\mathrm{T}_{e}$ between gate 1 and 2 (300 K over $36 \mathrm{~km}$ altitude difference) indicates a significant heating due to the low energy electron precipitation.

We are going to conclude that the $T_{i}=1700 \mathrm{~K}$ isocontour boundary represents a proxy for the polar-cap boundary, and in Sect. 3.1 we will relate the north-south zigzagging motion of that boundary to unbalanced dayside and nightside reconnection. Section 3.2 is devoted to a physical explanation for the prominent $\mathrm{T}_{i}$ channel that lasted several hours in the EISCAT f-o-v. In Sect. 3.3 we look more closely at the DMSP precipitation characteristics with respect to the openclosed field-line boundary, and discuss the potential of using $\mathrm{T}_{e}$ versus $\mathrm{T}_{i}$ gradients as a proxy for the open-closed field-line boundary. We are going to conclude that the $\mathrm{T}_{i}$ boundary represents a proper reference for calculating the reconnection rate.

\subsection{Dayside polar-cap boundary movement versus IMF $B_{Z}$}

Figure 8 presents the $\mathrm{T}_{i}=1700 \mathrm{~K}$ isocontour boundary on the equatorward edge of the high $\mathrm{T}_{i}$ band, for EISCAT Beam 1 and Beam 2 (upper and middle panels, respectively), along with variations in IMF $B_{Z}$ (bottom panel). The time axis for the IMF $B_{Z}$ variation has been shifted by one hour with respect to the $\mathrm{T}_{i}$-plots to adjust the time lag between ACE located $230 R_{E}$ upstream and the ionospheric response. This lag is calculated from the observed solar wind speed and, as discussed below, allows for various features observed by EISCAT to be matched up with causal IMF features. Up to about 08:00 UT, the latitudinal movements of the $\mathrm{T}_{i}$ boundary appear closely related to changes in IMF $\mathrm{B}_{Z}$. From 03:00 UT to 05:00 UT ACE observed a gradual decrease in $\mathrm{B}_{Z}$ from 0 to $-7.5 \mathrm{nT}$, giving rise to enhanced magnetopause
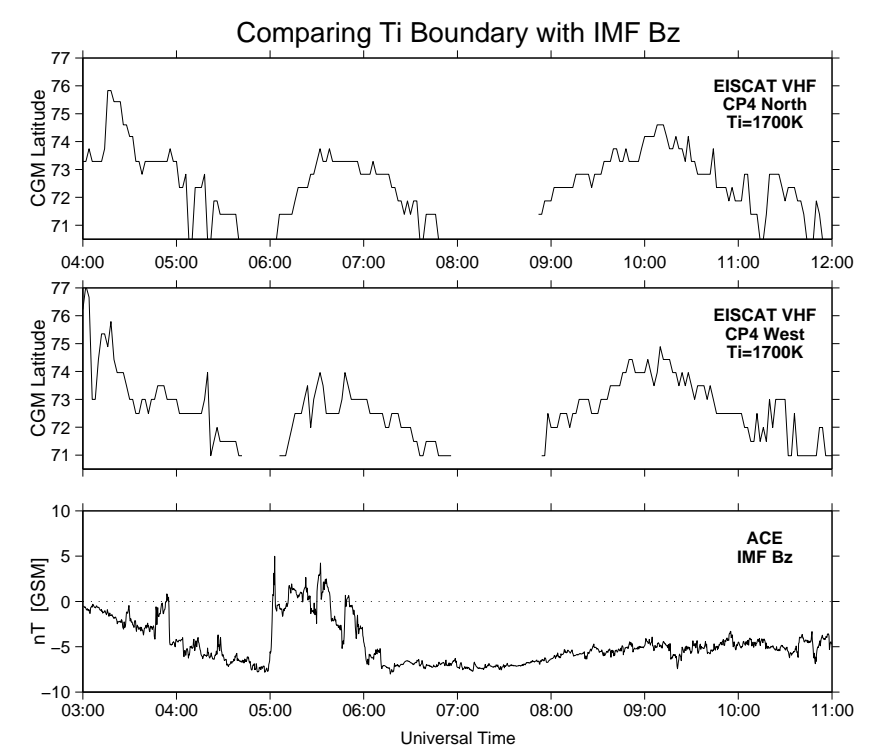

Fig. 8. The upper two panels show the $\mathrm{T}_{i}=1700 \mathrm{~K}$ isocontour boundary derived from EISCAT Beam 1 and Beam 2, and the bottom panel shows IMF $B_{Z}$ observed by ACE. Note that the ACE time scale is shifted by one hour relative to the EISCAT observations.

reconnection seen by the radar as an expansion of the polar cap from 04:00 to 06:00 UT. The sharp northward turning observed by ACE at 05:00 UT effectively stopped the production of new open flux. The poleward contraction of the polar cap from 06:00 and 06:40 UT appears consistent with the closure of flux by lobe reconnection on the dayside lobes. However, around the same time at 06:00 UT, a negative bay in the AL index peaked at $-460 \mathrm{nT}$ (not presented), and a much more likely explanation is a closure of flux by reconnection in the cross-tail current sheet. In this case, as IMF $\left|\mathrm{B}_{Y}\right|$ dominated IMF $\left|\mathrm{B}_{Z}\right|$ after the northward turning, lobe reconnection is expected to stir open flux oppositely in the two hemispheres rather than giving rise to closure of flux. Looking at the more-detailed structure in the response, it is interesting to note that the negative deflection in IMF $\mathrm{B}_{Z}$ observed by ACE between 05:40 and 05:50 UT lines up perfectly with the brief equatorward bounce in the $\mathrm{T}_{i}$ boundary in Beam 2 between 06:40-05:50 UT. If real, this boundary movement must have been local, as it was not evident in Beam 1. More significant, however, is the subsequent rapid decrease in $\mathrm{B}_{Z}$ from near zero to $-7 \mathrm{nT}$ from $\sim 05: 50$ to 06:00 UT (at ACE), after which the IMF $B_{Z}$ stayed negative throughout the time interval considered in this study. Enhanced magnetopause reconnection and efficient opening of flux migrated the $T_{i}$ boundary more than four degrees in latitude out of the radar f-o-v. When the boundary became detectable again at 08:50 UT, a rapid poleward retreat was observed until 10:15 UT. This can only be explained by tail reconnection and closure of flux. Between 08:08 UT and 08:28 UT the AL index dropped from -160 to $-990 \mathrm{nT}$, indicating strong tail reconnection. Based on the Dungey (1961) 
reconnection model, it has become well established that if the magnetopause reconnection rate exceeds the reconnection rate in the geomagnetic tail, the polar cap expands. Likewise, if the nightside reconnection rate exceeds that of the dayside, the polar cap size decreases. Siscoe and Huang (1985) established a model for how polar-cap boundary movement due to unbalanced dayside and nightside reconnection gives rise to excitation of large-scale polar cap convection. Cowley and Lockwood (1992) further refined a conceptual model to explain the impact of unbalanced, time-dependent reconnection on the generation of large-scale polar cap convection. Lockwood et al. (1988), Lester et al. (1990) and Fox et al. (1994) documented large-scale displacements of the polar-cap boundary in the 04:00-10:00 MLT sector, found expansion of the polar cap consistent with magnetopause reconnection, and ascribed contractions of the polar cap to substorm activity. In the case presented by Lester et al. (1990), the contraction occurred despite the fact that the IMF was strongly southward $\left(\mathrm{B}_{Z}\right.$ near $\left.-10 \mathrm{nT}\right)$. Milan et al. (2003) conducted a comprehensive study, including a global survey by the Polar Ultraviolet Imager (UVI) and SuperDARN HF radar, observing variations in the polar cap area as a function of changing IMF and substorm activity. In the time interval presented by Milan et al. (2003), IMF $B_{Z}$ was fluctuating between positive and negative values, and the major polar cap contraction event occurred during IMF $\mathrm{B}_{Z}$ north. The case presented in Fig. 8 provides a new example of this effect under different IMF conditions, where unbalanced reconnection dominated by tail gave rise to a rapid poleward contraction in the 12:00-13:00 MLT sector when IMF $B_{Z}$ stayed strongly negative.

\subsection{Ionospheric flow and plasma dynamics associated with} the high $\mathrm{T}_{i}$ channel

The band of high $\mathrm{T}_{i}$ was observed to be a persistent feature from 04:15 UT ( 07:25 MLT) until 12:00 UT ( $\sim 15: 10$ MLT), except for a half-hour break near magnetic noon at around 08:50 UT. This is taken as an indicative that the $\mathrm{T}_{i}$ channel was extended along most of the dayside auroral oval, and persistent in time. The latitudinal width of the $T_{i}$ band varied spontaneously from $1^{\circ}$ to $4^{\circ} \mathrm{CGM}$ Lat. The variation in width was particularly strong during intervals $\mathrm{A}$ and $\mathrm{C}$ when the $\mathrm{T}_{i}$ boundary migrated equatorward. $\mathrm{T}_{i}$ enhancements appear modulated by corresponding enhancements in the line-of-sight flow velocity. For example, during interval $\mathrm{C}$, a sequence of six $\mathrm{T}_{i}$ events is marked by arrows in Fig. 2c, and these seem all to be associated with a flow enhancement in Fig. 2d. The first five events were associated with bursts in the poleward flow, while the later event (near 08:00 UT) coincided with toward flow in Beam 1 but poleward flow in Beam 2 (Fig. 2e).

The combination of EISCAT $\mathrm{T}_{i}$ and DMSP F12 and F13 flow observations addresses the $\mathrm{T}_{i}=1700 \mathrm{~K}$ boundary to the equatorward edge of a strong flow disturbance (Figs. 3-6). F12 and F13 were, respectively, separated 1 and $2.5 \mathrm{~h}$ in magnetic local time east of the EISCAT f-o-v when they in- tersected the poleward edge of the flow channel. Furthermore, the signal-to-noise ratio of the radar pulse decreases with range, and the data quality becomes poorer at higher latitudes. Because of these uncertainties we will not focus on the observations near the poleward edge. However, the latitudinal width of the flow channel intersected by the two DMSP passes was about two degrees in latitude.

Pinnock et al. (1993) reported on a zonally-aligned narrow channel of enhanced convection, at least $900 \mathrm{~km}$ in longitudinal extent and $100 \mathrm{~km}$ wide. On the basis of combined data from the PACE HF radar in Antarctica, DMSP particle and drift meter, they located the flow channel to the equatorward part of the cusp precipitation region. They attributed flow bursts on the order of $3 \mathrm{~km} \mathrm{~s}^{-1}$ within this channel to candidate flux transfer events (FTEs). EISCAT observations of strong plasma flows in the auroral cusp were reported by Lockwood et al. (1990), and the phenomenon of latitudinally confined strong flows in the cusp has been reported by e.g. Valladares et al. (1994, 1999) and Pinnock et al. (1991).

Narrow zones of frictional heating may occur near the dayside and the nightside part of the auroral oval (Lockwood et al., 1988; Woodfield et al., 2002). The ion heating rate is proportional to the square of the ion-neutral gas velocity difference, and for relative velocities more than a $\mathrm{km} \mathrm{s}^{-1}$, the ion temperature is enhanced by over $\sim 1000 \mathrm{~K}$. This is what produces the hot ion channel. According to model results by Lockwood and Fuller-Rowell (1987a, b), if the neutral wind pattern had reached a diurnal equilibrium prior to expansion (contraction) of the polar cap, there will form a band of strong frictional heating immediately poleward (equatorward) of the expanding (contracting) flow-reversal boundary. This is because ion flow on the trailing edge of a moving convection boundary will meet neutral wind which has yet to respond to the change. Examples of this effect were demonstrated by Lockwood et al. (1988) and Fox et al. (1994). However, these examples were away from noon and required a strong shear CRB. This idea is not consistent with the nearnoon observations presented here except maybe for interval $\mathrm{D}$ (from 09:15-09:45 UT), where high $\mathrm{T}_{i}$ was located equatorward of the flow-reversal boundary as it retreated poleward (Figs. 2c and 2d). During the expansion in interval A, the band of high $\mathrm{T}_{i}$ region is located mainly equatorward of the flow-reversal boundary, or is sometimes straddling the flow-reversal boundary along the two radar beams (Figs. 2c2e), while according to the "trailing-edge" concept Joule heating should occur poleward of the flow-reversal boundary. For the F13 pass around 06:30 UT, high $\mathrm{T}_{i}$ spanned the flow-reversal boundary, with large ion flows on either side (Figs. 3 and 4). During interval C, the $\mathrm{T}_{i}$ band is not related to a flow-reversal boundary at all, but rather to a prominent acceleration in the poleward flow. The DMSP pass around 09:00 UT did not observe any flow shear, but instead a channel of strongly-enhanced anti-sunward flow (north-westerly oriented) in association with the $\mathrm{T}_{i}$-band. The 5-10 min. modulation of $\mathrm{T}_{i}$ is probably caused by pulsations in the convection electric field applied on the ionosphere, rather than the potential role of retarding ion and neutral flows. The fact 
that the polar-cap boundary was rapidly zigzagging in latitude means that it was unlikely that the near-noon neutral winds built up to a strong and steady pattern, which was a required condition for the model results by Lockwood and Fuller-Rowell (1987a, b).

The narrow gap in the $T_{i}$ channel near magnetic noon (between about 08:25 and 08:50 UT) indicates that the cusp trough has covered this MLT sector sufficiently long that the neutral wind has been speeded up to the same magnitude as the ion flow. Note that at $250 \mathrm{~km}$, the mean time for an ion to collide with a neutral particle is about a second; near $300 \mathrm{~km}$, a few seconds (e.g. Banks and Kockarts, 1973). If the ion gas is at rest in the neutral gas rest frame (no relative velocity of one with respect to the other), the ion temperature will come into equilibrium with the neutral gas temperature within a few collision times. If the ion gas is moving relative to the neutral gas, an ion colliding with a neutral will suffer redirection of some of its ordered motion, and this random redirection is ion heating. Now consider the time for the neutral gas to respond to ion gas moving through it and compare with the time of about a second for the ion gas to respond to collisions with the neutrals in which it is immersed. The mean time for a neutral particle to collide with an ion is longer than the mean time for an ion to collide with a neutral, by the ratio of the number of neutral particles per unit volume to the number of ions. At around $250-300 \mathrm{~km}$, the number density of atomic oxygen is near $10^{15} \mathrm{~m}^{-3}$, compared with the $10^{12} \mathrm{~m}^{-3}$ ion density in the $\mathrm{T}_{i}$ gap region. Thus, it takes about 1000 times longer for the neutrals to respond than the ions, i.e. $\sim 1000 \mathrm{~s}$. The nature of the response to a persistent ion flow is that a neutral particle continues with the initial ion velocity, and the ion starts life with the neutral particle velocity. This is because collisions are via a charge transfer reaction: an electron transfers from a neutral atomic oxygen particle to an atomic oxygen ion, and then they exchange roles. Thus, within about half an hour (a couple of collision times) the neutrals are up to speed with the plasma flow, for the $10^{12} \mathrm{~m}^{-3}$ ion density near local noon, where the highdensity plasma flow is entering the polar cap. This can only occur provided that high plasma density and enhanced flow persist for that long. The high-density plasma channel is well over an hour in width. The IMF orientation was stable from 06:00 UT onwards, corresponding to 07:00 UT onwards in the ionosphere, suggesting that the MLT location of the cusp inflow region might well have been stable for an extended time around the observed gap in high $\mathrm{T}_{i}$. Consequently, ion heating is absent (negligible relative velocity), and in addition, a huge channel of thermospheric flow is directed into the polar cap. At UTs prior to the high ion density cusp sector, the ion densities are only a few times $10^{11} \mathrm{~m}^{-3}$, and the neutrals would take hours to come up to speed, time they do not have. In going from an ion density of $10^{12} \mathrm{~m}^{3}$ to one of $10^{11} \mathrm{~m}^{-3}$, the collision time goes from of the order of half an hour to of the order one quarter of a day. Thus, the ions in the sunward flow region meet a thermosphere nearly at rest. With a response time of the ion-neutral collision time of $\sim 1 \mathrm{~s}$, the ion gas comes to a high equilibrium temperature con- trolled by strong ion winds. Likewise, post-magnetic noon, the ion densities fall sufficiently that the neutral-ion collision time exceeds the time a nominally co-rotating part of the thermosphere experiences a nominally constant plasma flow velocity vector, and again, the ion heating is controlled by high speed ions.

Cowley et al. (1991) discussed high-speed plasma flows immediately poleward of the open-closed field-line boundary in terms of the tension force on newly-opened magnetic field lines. Given that the high $\mathrm{T}_{i}$ is a signature of newlyopen flux, it should be pointed out that the eight hours of continuous observation of high $\mathrm{T}_{i}$ does naturally not imply that the longitudinal width of the cusp was eight hours at any one time. The ionospheric cusp reconfigures in response to changes in IMF within minutes (Moen et al., 1999, 2001). However, from the DMSP F13 we know that the cusp was at least five hours wide around 06:30 UT. Doe et al. (2001) reported a band of high $\mathrm{T}_{e}$ lasting for six hours observed by the Søndre Strømfjord radar. Milan et al. (2000) and Moen et al. (2001) observed moving cusp auroral signatures in the 16:00-17:00 MLT sector. So, cusp/open LLBL activity may occur in a wider span of local times than expected from the statistical survey provided by Newell and Meng (1992).

\subsection{Ionospheric signatures of the open-closed field-line boundary}

At 06:30 UT, DMSP F13 crossed a region of mixed magnetosheath and magnetospheric electrons prior to encountering the central plasma sheet (CPS). The region of mixed electron particle fluxes located on sunward return flow is a candidate low-altitude signature of the mixing layer reported by Fujimoto et al. (1998). They observed a thin mixing layer associated with sunward flow on the dawn flank (06:0009:00 MLT). It was situated between the central plasma sheet and the convection-reversal boundary, and was tentatively attributed to closed LLBL.

On both sides of the convection-reversal boundary in Fig. 3, there is a weak flux of $3-20 \mathrm{keV}$ ions on the top of the intense flux of low-energy magnetosheath ions. Lockwood and Moen (1996) explained the mixture of magnetospheric and magnetosheath ions by introducing a reconnection model that includes interior and exterior rotational discontinuities (Alfvén waves) emanating from the reconnection line. Their model results showed that magnetospheric ions can be injected on open LLBL field lines by reflection of the pre-existing magnetosphere by the interior Alfvén wave. The mixing of magnetospheric and magnetosheath electrons is not well understood. The poleward boundary of highenergy electrons has traditionally been taken as a marker of the open-closed field-line boundary, as magnetospheric electrons on newly-open field lines are expected to escape within one-quarter of a bouncing period, i.e. within seconds. Oksavik et al. (2000) demonstrated an ambiguity problem by applying the above rule of thumb for identifying the open-closed boundary. An isotropic flux of energetic electrons was observed on field-line-associated magnetosheath 
particle injection and a staircase ion-dispersion signature. The staircase ion cusp and poleward moving auroral forms are regarded as key signatures of transient magnetopause reconnection (Newell and Meng, 1991, 1995; Lockwood and Smith, 1992; Onsager et al., 1993; Farrugia et al., 1998; Lockwood and Davis, 1995; Lockwood et al., 1998), while energetic electrons are used as a tracer of closed flux.

Lockwood (1998) put forward a possible explanation for a mixing layer on sunward convection immediately poleward of the open-closed field-line boundary, which is entirely consistent with the observations presented here. The flow-reversal boundary marks out the location where the interior Alfvén wave arrived. It may take several Alfvén wave bounces until sufficient momentum has been carried down to change the direction of the ionospheric flow from sunward to antisunward, i.e. the newly-open flux continues to stream sunward several minutes after being opened. Super-Alfvénic sheath particles (electrons and the more energetic ions) will arrive before any change in the flow and the CRB may not be complete until several bounces of the interior Alfvén wave. Notable from Fig. $3 b$ is that the energetic electron population bordered on the prenoon LLBL but not on the postnoon LLBL/Cusp. The CPS population tails off within the mixing layer, which indicates that ring current electrons have penetrated the LLBL boundary by gradient-B and curvatureB drifts, which are breakdowns of the frozen-in approximation. Interestingly, the highest energy of this population decreases with increasing latitude, which means that the highest energies are emptied first. Gradient-B and curvature-B drifts of electrons onto newly-opened field lines may continue as long as a contact surface exists between the open and closed fluxes. It has also been postulated that magnetospheric particle fluxes can be maintained by magnetic bottles on open field lines, as the field strength has a minimum at middle latitudes in the magnetic cusp (Cowley and Lewis, 1990; Scholer et al., 1982; Daly and Fritz, 1982). Nishida et al. (1993) reported open-flux characteristics on sunward return flow. According to Lockwood (1998) the mixing layer is on open field lines, located between the central plasma sheet and the flow-reversal boundary.

From the observations presented here, it is possible to discuss the general location of the reconnection site. Earlier in Sect. 3, we noted that DMSP F13 observed the CRB and the equatorward edge of the high flow band $\left(\mathrm{T}_{i}=1700 \mathrm{~K}\right)$ to be, respectively, $2.7^{\circ}$ and $1.2^{\circ}$ poleward of the electron edge, which is taken to be an indicator of the OCB. These latitude differences correspond to northward distance $\mathrm{d}_{n}$ of 300 and $130 \mathrm{~km}$. Because of the lack of a strong ion dispersion signature, we can assume that the along track convection component is small, so the flow speed $\mathrm{V}_{c}$ is similar to the crosstrack component (of the order of $1 \mathrm{~km} \mathrm{~s}^{-1}$ ). From this, the northward component of the flow $\mathrm{V}_{c n}$ is about $0.5 \mathrm{~km} \mathrm{~s}^{-1}$ (a similar value is derived in this region using the EISCAT line-of-sight velocities). If we take the equatorward edge of the high flow/high- $\mathrm{T}_{i}$ band to be where the flow begins to change because of the arrival of the interior Alfvén wave, this means that the wave took $260 \mathrm{~s}$ longer to reach the iono- sphere than the first electrons. We see sheath electrons at all energies down to $30 \mathrm{eV}$ at this edge (a field-aligned speed of $\mathrm{V}_{e}=3200 \mathrm{~km} \mathrm{~s}^{-1}$ ) and we here assume the Alfvén wave to travel at an average speed of $\mathrm{V}_{A}=1000 \mathrm{~km} \mathrm{~s}^{-1}$. The difference in travel times of the wave and the edge electrons is $\left(\Delta \mathrm{t}_{A}-\Delta \mathrm{t}_{e}\right)=\mathrm{d}\left(\mathrm{V}_{A}^{-1}-\mathrm{V}_{e}^{-1}\right)$, where $\mathrm{d}$ is the field-aligned distance to the reconnection site. For a poleward convection speed $\mathrm{V}_{c n}$, this time difference corresponds to a latitudinal distance $\mathrm{d}_{n}=\left(\mathrm{d}_{A}-\mathrm{d}_{e}\right)=\mathrm{V}_{c n}\left(\Delta \mathrm{t}_{A}-\Delta \mathrm{t}_{e}\right)$. Thus,

$\mathrm{d}=\left(\mathrm{d}_{n} / \mathrm{V}_{c n}\right) /\left(\mathrm{V}_{A}^{-1}-\mathrm{V}_{e}^{-1}\right)$.

Substituting the above values into Eq. (1) yields $\mathrm{d}$ of $\sim 60 R_{E}$, that the electron edge is $\mathrm{d}_{e}=60 \mathrm{~km}$ poleward of the actual magnetic footprint of the $\mathrm{X}$-line, and the arrival of the wave is $\mathrm{d}_{A}=190 \mathrm{~km}$ poleward of the OCB. Note that a reflected "second-bounce" Alfvén wave would return to the ionosphere after about $3 \Delta t_{A}$ after reflection from the (open) magnetopause and so would be at least three times this distance from the OCB. Thus, such an effect is not an explanation of the $\mathrm{CRB}$ which is here estimated to be $360 \mathrm{~km}$ from the OCB. The large d derived clearly indicates a reconnection site on the flank of the magnetosphere.

The two DMSP snapshots indicated a relationship between elevated $\mathrm{T}_{e}$ near the equatorward edge of magnetosheath electron precipitation, which is consistent with earlier work (cf. Introduction). However, one should exercise caution when employing $\mathrm{T}_{e}$ as a marker for precipitation boundaries, in particular for the geometry of the EISCAT CP-4 experiment when we do not have altitude profiles. Carlson (1998) pointed out that the cooling rate of electrons is proportional to the square of the electron density, and for electron densities much above $3 \times 10^{11} \mathrm{~m}^{-3}$, the electron gas is in good thermal contact with the ion gas. Based on the energy equation from Banks and Kockarts (1973), Doe et al. (2001) demonstrated that electron cooling may suppress the $\mathrm{T}_{e}$ signature below $400 \mathrm{~km}$. We do see an example of this in the present data set, where we see "bite-outs" in the high electron temperatures associated with the tongue of ionization. After about 09:20 we see another complexity, that is, the elevation of $\mathrm{T}_{e}$ due to sunrise and solar illumination, and the $\mathrm{T}_{e}$ boundary fails for this reason to be a simple boundary marker.

In general, $\mathrm{T}_{e}$ can serve as a simple particle-precipitation boundary marker when other electron gas heating terms are absent, and electron cooling rates are modest (ion densities near and below about $3 \times 10^{11} \mathrm{~m}^{-3}$ ). For other conditions, more careful analysis of the thermal balance is needed to draw conclusions about boundaries.

\section{Summary and concluding remarks}

The narrow channel of Joule heating indicates that the transfer of momentum from the solar wind to the ionosphere takes place in a latitudinally confined region. This has earlier been reported as a cusp phenomenon, but the near to eight-hour continuous observation by the EISCAT VHF radar on 23 
November 1999 is quite unusual, and gave us a unique opportunity to test ionospheric electron and ion temperature gradients as markers for the open-closed field-line boundary. The north-south zigzagging was found to be entirely consistent with the Cowley-Lockwood model of unbalanced dayside and nightside reconnection rates. This data set provides a first experimental evidence of a rapid poleward contraction of the noon polar cap boundary under IMF $\mathrm{B}_{z}$ south conditions.

The ionospheric electron temperature is sensitive to the precipitation of magnetosheath electron fluxes, as earlier demonstrated by the Søndre-Strømfjord and EISCAT Radar data and by modelling. The equatorward boundary of high $\mathrm{T}_{e}$ may sometimes serve as the initial marker of newly-opened flux. However, $\mathrm{T}_{e}$ may fail as an open-closed boundary marker in cases when: 1) the electron density is significantly above $3 \times 10^{11} \mathrm{~m}^{-3}$ (Carlson et al., 1998) (the $\mathrm{T}_{e}$ boundary is then generally suppressed at altitudes below $\sim 400 \mathrm{~km}$, cf. Doe et al., 2001); 2) the electron plasma is heated by solar illumination; 3) the electron plasma is heated by high ion temperatures; and 4) the electron plasma is heated by downward heat conduction from a large heat reservoir in the flux tube above the F-region, as for a currently or previously closed magnetic flux tube that has not had time to cool. Note that $\mathrm{L}$ $\sim 6$ flux tubes can take hours to cool down after both feet of the flux tube are no longer sunlit, at which time photoelectron heating of the ambient electron gas within the tube turns off. Due to changing conditions for thermal balance during the interval of interest here, we did not succeed with using $\mathrm{T}_{e}$ as a tracker the open-closed boundary. A major limitation for the EISCAT VHF convection experiment in this context is the lack of altitude profiles.

We conclude that the equatorward edge of the high $\mathrm{T}_{i}$ channel manifests the arrival of the rotational discontinuity. The gap between the equatorward $\mathrm{T}_{i}$ boundary and the equatorward edge of magnetosheath electron edge was $\sim 60 \mathrm{~km}$ near 12:00 MLT (DMSP F12) and $130 \mathrm{~km}$ near 10:00 MLT (DMSP F13). The distance between the arrival of the first (super-Alfvénic) magnetosheath electrons and the transfer of momentum carried by Alfvén waves will naturally depend on magnetic field line distance between the magnetopause $\mathrm{X}$-line and the ionospheric counterpart, as well as the convection speed at the ionospheric end. In general, this distance will increase away from magnetic noon. In cases when release of magnetic tension gives rise to significant Joule heating, the equatorward $\mathrm{T}_{i}$ boundary is the actual reference boundary to be used for calculating the reconnection rate. This will be treated in a separate publication by Lockwood et al. (2003).

The region of mixed magnetosheath and magnetospheric electrons between the convection reversal boundary and the electron edge, on sunward convecting flux, is a candidate footprint of the low-latitude boundary mixing layer on open field lines.
Acknowledgements. EISCAT is an international association supported by Finland (SA), France (CNRS), the Federal Republic of Germany (MPG), Japan (NIPR), Norway (NFR), Sweden (NFR), and the United Kingdom (PPARC). We thank the ACE Science Center and the ACE MAG and SWEPAM instrument teams for providing solar wind data from the ACE spacecraft. The work has received financial support from the Norwegian Research Council and AFOSR task 2311AS.

\section{References}

Banks, P. M. and Kockarts, G.: Aeronomy, Academic Press, New York, 1973.

Brace, L. H., Theis, R. F., and Hoegy, W. R.: A global view of the F-region electron density and temperature at solar maximum, Geophys. Res. Lett., 9, 989-992, 1982.

Carlson, H. C.: Response of the polar cap ionosphere to changes in (solar wind) IMF, Polar-cap boundary Phenomena, by Moen, J., Egeland, A., and Lockwood, M. (eds.) NATO Advanced Study Institute Series, Kluwer Academic Press, Dordrect, Vol. 509, 255-270, 1998.

Cowley, S. W. H. and Lewis, Z. V.: Magnetic trapping of energetic particles on open dayside boundary layer flux tubes, Planet. Space Sci., 38, 1343-1350, 1990.

Cowley, S. W. H., Morelli, J. P., and Lockwood, M.: Dependence of convective flows and particle precipitation in the high-latitude dayside ionosphere on the $\mathrm{X}$ and $\mathrm{Y}$ components of the interplanetary magnetic field, J. Geophys. Res., 96, 5557-5564, 1991.

Cowley, S. W. H. and Lockwood, M.: Excitation and decay of solar wind-driven flows in the magnetosphere-ionosphere system, Ann. Geophys., 10, 103-115, 1992.

Curtis, S. A., Hoegy, W. R., Brace, L. H. et al.: DE-2 cusp observations: role of plasma instabilities in topside ionospheric heating and density fluctuations, Geophys. Res. Lett., 9, 997-1000, 1982.

Daly, P. W. and Fritz, T. A.: Trapped electron distributions on open field lines, J. Geophys. Res., 87, 6081-6088, 1982.

Davies, J. A., Yeoman, T. K., Rae, I. R., Milan, S. E., Lester, M., Lockwood, M., and McWilliams, A.: Ground-based observations of the auroral zone and polar cap ionospheric responses to dayside transient reconnection, Ann. Geophys., 20, 781-794, 2002.

Davis, C. J. and Lockwood, M.: Predicted signatures of pulsed reconnection in ESR data, Ann. Geophys., 14, 1246-1256, 1996.

Doe, R. A., Kelly, J. D., and Sánchez, E. R.: Observations of persistent dayside F-region electron temperature enhancements associated with soft magnetosheathlike precipitation, J. Geophys. Res., 106, 3615-3630, 2001.

Dungey, J. W.: Interplanetary magnetic field and the auroral zones, Phys. Rev. Lett., 6, 47 -48, 1961.

Farrugia, C. J., Sandholt, P. E., Denig, W. F., and Torbert, R.: Observation of a correspondence between poleward-moving auroral forms and stepped cusp ion precipitation, J. Geophys. Res., 103, 9309-9315, 1998.

Fox, N. J., Lockwood, M., Cowley, S. W. H., Freeman, M. P., FriisChristensen, E., Milling, D. K., Pinnock, M., and Reeves, G. D.: EISCAT observations of unusual flows in the morning sector associated with weak substorm activity, Ann. Geophys., 12, 541553, 1994.

Fujimoto, M., Mukai, T., Kwano, H., Nakamura, M., Nishida, A., Saito, Y., Yamamota, T., and Kokubun, S.: Structure of the low 
latitude boundary layer: A case study with Geotail data, J. Geophys. Res., 103, 2297-2308, 1998.

Heppner, J. P. and Maynard, N.C.: Empirical high-latitude electric field models, J. Geophys. Res., 92, 4467-4490, 1987.

Lester, M., Freeman, M. P., Southwood, D. J., Waldock, J. A., and Singer, H. J.: A study of the relationship between interplanetary parameters and large displacements of nightside polar-cap boundary, J. Geophys. Res., 95, 21 133-21 145, 1990.

Lockwood, M.: Identifying the open-closed field-line boundary, Polar-cap boundary Phenomena, edited by Moen, J., Egeland, A., and Lockwood, M. (eds.), NATO Advanced Study Institute Series, Kluwer Academic Press, Dordrect, Vol. 509, 415-432, 1998.

Lockwood, M. and Smith, M. F.: The variation of reconnection rate at the dayside magnetopause and cusp ion precipitation, J. Geophys. Res., 97, 14 841-14 847, 1992.

Lockwood, M. and Davis, C. J.: Occurence probability, width and number of steps of cusp precipitation for fully pulsed reconnection at the dayside magnetopause, J. Geophys. Res., 100, 7627$7640,1995$.

Lockwood, M. and Fuller-Rowell, T. J.: The modelled occurrence of non-thermal plasma in the ionospheric F-region and the possible consequences for ion outflows into the magnetosphere, Geophys. Res. Lett., 14, 371-374, 1987a.

Lockwood, M. and Fuller-Rowell, T. J.: Correction to "The modelled occurrence of non-thermal plasma in the ionospheric Fregion and the possible consequences for ion outflows into the magnetosphere", Geophys. Res. Lett., 14, 581-581, $1987 \mathrm{~b}$.

Lockwood, M. and Moen, J.: Ion populations on open field lines within the low-latitude boundary layer: theory and observations during a dayside transient event, Geophys. Res. Lett., 23, 28952898, 1996.

Lockwood, M., Cowley, S. W. H., Todd, H., Willis, D. M., and Clauer, C. R.: Ion flows and heating at a contracting polar-cap boundary, Planet. Space Sci., 36, 1229-1253, 1988.

Lockwood, M., Cowley, S. W. H., and Freeman, M. P.: The excitation of plasma convection in the high-latitude ionosphere, J. Geophys. Res., 95, 7961-7972, 1990.

Lockwood, M., Denig, W. F., Farmer, A. D., Davda, V. N., Cowley, S. W. H., and Lühr, H.: Ionospheric signatures of pulsed magnetic reconnection at the Earth's magnetopause, Nature, 361, (6411), 424-428, 1993.

Lockwood, M., Opgenoorth, H., van Eyken, A. P., Fazakerley, A., Bosqued, J.-M., Denig, W. F., Wild, J., Cully, C., Greenwald, R., Lu, G., Amm, O., Frey, H., Strømme, A., Prikryl, P., Hapgood, M. A., Wild, M. N., Stamper, R., Taylor, M., McCrea, I., Kauristie, K., Pulkinnen, T., Pitout, F., Balogh, A., Dunlop, M., Rème, H., Behlke, R., Hansen, T., Provan, G., Eglitis, P., Morley, S. K., Alcayde, D., Blelly, P.-L., Moen, J., Donovan, E., Engebregtson, M., Lester, M., Waterman, J., and Marcucci, M. F.: Coordinated Cluster, ground-based instrumentation and low-altitude satellite observations of transient poleward moving events in the ionosphere and the tail lobe, Ann. Geophys., 18, 1589-1612, 2001.

McCrea, I. W., Lockwood, M., Moen, J., Pitout, F., Eglitis, P., Aylward, A. D., Cerisier, J.-C., Thorolfssen, A., and Milan, S. E.: ESR and EISCAT observations of the response of the cusp and cleft to IMF orientation changes, Ann. Geophys., 18, 1009-1026, 2000.

Milan, S. E., Lester, M., Cowley, S. W. H., and Brittnacher, M.: Convection and auroral response to a southward turning of the IMF: Polar UVI, CUTLASS, and IMAGE signatures of transient magnetic flux transfer at the magnetopause, J. Geophys. Res., 105, 15 741-15 755, 2000.

Milan, S. E., Lester, M., Cowley, S. W. H., Oksavik, K., Brittnacher, M., Greenwald, R. A., Sofko, G., and Villain, J.-P.: Variations in the polar cap area during two substorm cycles, Ann. Geophys., 21, 1121-1140, 2003.

Moen, J., Carlson, H. C., and Sandholt, P. E.: Continuous Observation of Cusp Auroral Dynamics in Response to an IMF $\mathrm{B}_{Y}$ Polarity Change, Geophys. Res. Lett., 26, 1243-1246, 1999.

Moen, J., Carlson, H. C., Milan, S., Shumilov, N., Lybekk, B., Sandholt, P. E., and Lester, M.: On the colocation between dayside auroral activity and coherent HF backscatter, Ann. Geophys., 18, 1531-1549, 2001.

Newell, P. T. and Meng, C.-I.: Mapping the dayside ionosphere to the magnetosphere according to particle precipitation characteristics, Geophys. Res. Lett., 19, 609-612, 1992.

Newell, P. T. and Meng, C.-I.: Cusp low-energy cutoffs: A survey and implications for merging, J. Geophys. Res., 100, $21943-$ $21951,1995$.

Newell, P. T., Burke, W. J., Sanchez, E. R., Meng, C.-I., Greenspan, M. E., and Clauer, C. R.: The low-latitude boundary layer and the boundary plasma sheet at low altitude: Dayside precipitation regions and convection reversal boundaries, J. Geophys. Res., 96, $21013-21023,1991$.

Nilsson, H., Yamauchi, M., Eliasson, L., and Norberg, O., and Clemmons, J.: Ionospheric signature of the cusp as seen by incoherent scatter radar, J. Geophys. Res., 101, 10 947-10 963, 1996.

Nishida, A., Mukai, T., Hayakawa, H., Matsuoka, A., and Tsuruda, $\mathrm{K}$.: Unexpected features of the ion precipitation in the so-called cleft/low-latitude boundary layer region: association with sunward, convection and occurence on open field lines, J. Geophys. Res., 98, 11 161-11 176, 1993.

Onsager, T. G., Kletzing, C. A., Austin, J. B., and MacKiernan, H.: Model of magnetosheath plasma in the magnetosphere: Cusp and mantle particles at low altitudes, Geophys. Res. Lett., 20, 479 482, 1993.

Oksavik, K., Søraas, F., Moen, J., and Burke, W. J.: Optical and particle signatures of magnetospheric boundary layers near magnetic noon: Satellite and ground-based observations, J. Geophys. Res., 105, 27 555-27 568, 2000.

Pinnock, M., Rodger, A. S., Dudeney, J. R., Greenwald, J. R., Baker, K. B., Ruohoniemi, J. M.: An ionospheric signature of possible enhanced magnetic-field merging on the dayside magnetopause, J. Atmos. Terr. Phys., 53, 201-212, 1991.

Pinnock, M., Rodger, A. S., Dudeney, J. R., Baker, K. B., Newell, P. T., Greenwald, R. A., and Greenspan, M. E.: Observations of an enhanced convection channel in the cusp ionosphere, J. Geophys. Res., 98, 3767-3776, 1993.

Pryse S. E., Smith, A. M., Walker, I. K., and Kersley, L.: Multiinstrument study of footprints of magnetopause reconnection in the summer ionosphere, Ann. Geophys., 18, 1118-1127, 2000.

Sandholt, P. E., Denig, W. F., Farrugia, C. J., Lybekk, B., and Trondsen, E.: Auroral structure at the cusp equatorward boundary: Relationship with the electron edge of low-latitude boundary layer precipitation, J. Geophys. Res., 107, 1235, doi:10.1029/2001JA005081, 2002.

Scholer, M., Daly, P. W., Pashmann, G., and Fritz, T. A.: Field line topology determined by energetic particles during a possible reconnection event, J. Geophys. Res., 87, 6073-6080, 1982.

Siscoe, G. L. and Huang, T. S.: Polar cap inflation and deflation, Geophys. Res. Lett., 90, 543-547, 1985.

Titheridge, J. E.: Ionospheric heating beneath the magnetosphereic 
cleft, J. Geophys. Res., 81,3221-3226, 1976.

Valladares, C. E., Basu, S., Buchau, J., and Friis-Christensen, E.: Experimental evidence for the formation and entry of patches into the polar cap, Radio Sci., 29, 167, 1994.

Valladares, C. E., Alcaydé, D., Rodriguez, J. V., Ruohoniemi, J. M., and van Eyken, A. P.: Observations of plasma density structures in association with the passage of traveling convection vortices and the occurrence of large plasma jets, Ann. Geophys., 14, 1020-1039, 1999.

Vontrat-Reberac, A., Fontaine, D., Blelly, P. L., and Galand, M.: Theoretical predictions of the effect of cusp and dayside precipitation on the polar ionosphere, J. Geophys. Res., 106, $28857-$ $28865,2001$.
Waterman, J., Lummerzheim, D., de la Beaujardiere, O., Newell, P. T., and Rich, F. J.: Ionospheric footprint of magnetosheathlike particle precipitation observed by an incoherent scatter radar, J. Geophys. Res., 99, 3855-3867, 1994.

Wickwar, V. B. and Kofman, W.: Dayside auroras at very high latitudes: the importance of thermal excitation, Geophys. Res. Lett., 11, 923-926, 1984.

Woodfield, E. E., Davies, J. A., Eglitis, P., and Lester, M.: A case study of HE radar spectral width in the post midnight magnetic local time sector and its relation to the polar cap boundary, Ann. Geophys., 20, 501-509, 2002. 